\title{
A Study on Reflective Reciprocal Peer Coaching for Pre-service Teachers: Change in Reflectivity
}

\author{
S. Ipek Kuru Gonen \\ Correspondence: S. Ipek Kuru Gonen, Anadolu University, Faculty of Education, Department of ELT, 26470, Eskisehir, \\ Turkey.
}

Received: March 14, 2016 Accepted: April 2, $2016 \quad$ Online Published: April 24, 2016

doi:10.11114/jets.v4i7.1452

URL: http://dx.doi.org/10.11114/jets.v4i7.1452

\begin{abstract}
Reflective practice is considered as an effective way for professional development in order to gain awareness of one's own teaching as well as to compete with the changing needs of the students. Especially in pre-service period, when pre-service teachers work cooperatively with their peers in a reciprocal fashion towards reflectivity, it has a potential to promote advancement in reflective practices and help them focus on the underlying meaning behind their actions. Based on these ideas, this study aimed at engaging pre-service teachers in a reflective reciprocal peer coaching experience and investigating whether such experience caused any changes in their reflectivity. For this purpose, 12 pre-service teachers in a Turkish ELT context participated in the study and a reflective reciprocal peer coaching program was implemented with a training aspect. In a mixed method study design, change in participants' reflectivity was measured with a profile of reflective thinking attributes scale quantitatively and data were supported qualitatively with reflective diaries, video recordings of post-conference sessions and focus-group interviews. Results of quantitative and qualitative analyses put forward that the pre-service teachers advanced in their reflectivity throughout the reflective reciprocal peer coaching practice and benefited much from this experience before they embark into professional life. This study provides valuable implications to use reflection embedded in a peer coaching program and offers suggestions for teacher educators.
\end{abstract}

Keywords: reflective teaching, pre-service teacher education, peer coaching and reflective practices

\section{Introduction}

Teacher development is a process which requires an on going acquisition of new knowledge by critically reflecting on learning, actively taking part in classroom research, and interacting with colleagues. Teachers in pre-service period also need to be engaged in continuous process of improvement to enhance their teaching ability before they embark into the professional teaching life. At this point, field experience has a potential for providing pre-service teachers (PSTs henceforth) opportunities to instructional decision-making and improvement (Moore, 2003; Anderson, Barksdale \& Hite, 2005).

Field experience in this paper refers to the teaching experiences of PSTs in the assigned schools within teacher education programs (Lamaster, 2001; Puckett \& Anderson, 2002; He, Means \& Lin, 2006). Throughout this experience, the prospective teachers work with cooperating teachers at schools and are under the guidance of university supervisors who provide feedback. Field experience does not only serve as a bridge between theory and practice but it provides a valuable context in which PSTs develop a personal competence (Puckett \& Anderson, 2002; Smith \& Lev-Ari, 2005). According to Rowland, Lockyer, Carter, Patterson and Hearne (2000), field experience has been under considerable pressure to be reduced as a result of changes to university budgets, demands on lecturers to increase research and less staff in education faculties for supervision.

In addition to time constraints and limited utilities, receiving feedback from a cooperating teacher or a supervisor may provoke anxiety (Shantz \& Ward, 2000) and deprive the PSTs of an invaluable opportunity of working together and learning from each other. Moreover, such feedback from an authority is on a limited basis and mostly done in an evaluative manner (Trautwein \& Ammerman, 2010). Observations carried out by peer PSTs are more stress-free and enjoyable since these observations are based on mutual understanding and growth (Beavers, 2001; Prince, Snowden \& Matthews, 2010).

In this respect, different types of coaching that include interaction among peers are introduced in the literature (Robbins, 
1991; Donnelly, 2007; Britton \& Anderson, 2010). One of such coaching is Reflective Reciprocal Peer Coaching (RRPC henceforth) applied in this study. In order to design such a coaching program during the field experiences of pre-service teachers, the most important underlying issue is the improvement of reflective thinking skills and the ability of reflecting on the teaching practices. The aim of this study; therefore, was to engage PSTs in a RRPC program and to find out whether such program would make any difference in the improvement of their reflectivity.

\subsection{Reflection and Reflective Teaching}

In Dewey's (1933) terms, reflection is an active process, and it involves the willingness to take action for personal development, change and self-appraisal (Pollard \& Tann, 1994). In an educational sense, reflective thinking is "making informed and logical decisions on educational matters, then assessing the consequences of those decisions" (Taggart \& Wilson, 2005:1). It has been emphasized that reflective practice is a primary condition to achieve professional improvement development in the quality of teaching (Weshah, 2007) and it dominates teacher education around the world lately (Farrell, 2008; Gun, 2011). However, it is not easy for teachers to be engaged in reflective practice without necessary information and practice opportunities. In order to promote reflective practice for teachers, one should know the different modes of reflection hierarchy: technical level, contextual level, and dialectical level (Taggart \& Wilson, 2005).

Practitioners at the technical level use minimal schema to draw on while dealing with the problems whereas practitioners in the contextual level understand concepts, contexts, and theoretical bases for classroom practices, then defend those practices and articulate their relevance to student growth. The third, and the highest, level in the pyramid requires a critical reflection allowing practitioners to look for and analyze knowledge systems and theories in context and in relation to one another. The third level is similar to what Murray and Kujundzic (2005) call as the level of 'critical reflection' which involves the process of analyzing, reconsidering and questioning experiences within a broad context of issues such as analyzing assumptions about teaching, raising awareness about the context of teaching, imagining alternative ways of thinking, and reflectively questioning the effects and outcomes of teaching practices in a wider social perspective. Likewise, Gale and Jackson (1997) state that critical reflection involves concerns about broader issues of teaching and learning.

Based on the effectiveness of reflective practice, the aim of teacher education should focus on leading teachers to move from a technical level of reflectivity to level of contextual and dialectical/critical reflectivity. Hence, this categorization of reflectivity was considered as a starting point for the purposes of this study. However, such move from technical to critical level requires time, training, personal involvement, and opportunities for reflective practices (Chen, Lumpe \& Bishop, 2013). Such an opportunity would be working collaboratively with peers for effective reflective practices.

\subsection{Reflective Reciprocal Peer Coaching}

One type of collaboration is called peer coaching. On its basic terms, in this type of collaborative action teachers at equal status observe each other and contribute to the improvement of teaching skills through collaborative engagement. It is emphasized that engaging in peer coaching has the potential for sustaining reflection and enhancing teachers' ability to analyze the teaching practices (Huston \& Weaver, 2008; Lu, 2010). Anderson et al. (2005) highlight the reflective nature of peer coaching and assume that during field experience of PSTs, it sharpens observations and make them more meaningful by increasing skills of analysis and reflection.

Throughout reflective peer coaching, teachers not only meet and talk about each others' teaching experiences, but rather they systematically revise their own teaching and reflect critically upon their experience in a non-threatening atmosphere. In return, they may have a chance to see how their actions affect student learning in the classroom, what they may do to improve their teaching skills and learn from one another. When peer coaching is conducted in a reciprocal fashion, pairs or triads of teachers who have similar expertise and mentoring skills work together to utilize shared problem solving skills and support each other's' professional growth (Joyce \& Showers, 2002; Trautwein \& Ammerman, 2010). What is more, teachers take turns being a teacher coach and a coached teacher. According to Millis (1999), when peers observe each other in a reciprocal way, it guarantees the positive approach necessary for constructive change and it spurs learning about teaching.

Reciprocal peer coaching helps coaches act in a more cooperative way than when they receive feedback from someone in a position of authority (Ladyshewsky \& Ryan, 2002b; Topping, 2005). Zwart, Wubbels, Bergen and Bolhuis (2007) propose that reciprocity is the key for the success of a peer coaching program and it may help teachers to acquire the skills, knowledge, attitudes and values they need to improve for better student learning. Based on the ideas of reflectivity and reciprocity for the success of a peer coaching program, RRPC experience in this study aims to enhance reflective practices during peer coaching activities and is depended on the mutual sharing of ideas on an equal basis.

According to Little (2005), in order for peer coaching to be successful, teachers' developing a reflective attitude is 
crucial. Otherwise, the negative beliefs and experiences of teachers without any reflective practice while coaching each other would prevail the invaluable learning and teaching opportunities to be achieved. Similarly, Britton and Anderson (2010) assume that reflection is critical for the effectiveness of peer coaching as it allows to deepen understanding and challenge ideas related to teaching. Hence, RRPC can help to achieve the desired outcomes of reflective practice and peer coaching for teacher development. When peer coaching is based on reflection and reciprocity, it has a potential to help PSTs improve themselves in many aspects during their field experience.

In PST education context, the effects of peer coaching experiences on reflective practices are investigated by many researchers. The studies focusing on how engaging in peer coaching activities affected the reflective practices of PSTs tried to shed light on how levels of reflection can be improved through the use of peer coaching, how peers and supervisors contribute to improvement in reflectivity, and how different activities and tools can help PSTs become more reflective throughout peer coaching.

Cook, Young and Evensen (2001) investigated the effects of supervisors and peers on reflectivity and teacher effectiveness. When PSTs were involved in supervisory conferences, reflective thinking was not linked to improved teaching performance and the impacts of changes could not be easily seen in classroom performance. Furthermore, PSTs reflective thinking was generally in the technical level. In a second study, when PSTs were instructed about peer mediation and then paired to share their reflection reports with each other by mediating learning of each other, it had no immediate effect on their level of reflectivity. However, they needed more time and opportunity to improve their reflective abilities. All in all, Cook et.al's (2001) study asserted that even limited mediated learning experience, either in the format of supervisor mediation or peer mediation, was helpful in drawing attention to various aspects of reflection. Nevertheless, results imply that more time is required for the success of peer mediation and careful guidance and planning are necessary for better results in reflective practices.

One problem while implementing reflective peer coaching is student teachers' lack of ability to make connections between what has been learned in theory and what is actually taking place during the action of teaching. Thus, field experiences of PSTs can serve as a valuable opportunity to promote reflective thinking practice and effective peer coaching to bridge the gap between theory and practice (Kauffman, 1992; Puckett \& Anderson, 2002). In order to overcome the potential problems faced during linking the theory with practice, Griffin (2003) conducted a study to determine the effects of critical incidents and associated instructional activities on the reflective abilities of PSTs. This study put forward that most of the incidents were in a technical or contextual mode rather than dialectical. Moreover, when PSTs were asked about the improvement in their reflective ability, it was revealed that critical incidents and instructional activities increased their reflective abilities. Griffin's (2003) study imply the need for the improvement in the reflectivity levels of the PSTs through the design and implementation of activities that would guide them reflectively evaluate the effectiveness of field experience.

Vacilotto and Cummings (2007) also highlighted the reflective nature of peer coaching and focused on investigating the effectiveness of peer coaching as a professional development tool for pre-service ESL/EFL teachers. The results implied that peer coaching facilitated the exchange of teaching methods, materials, approaches, and techniques. Furthermore, peer coaching was found to foster teaching skills through observation and discussions and it led them become aware of what they did and improved flexibility. One of the important results of this study was that the PSTs were able to revise their ideas and old principles and adopted new ones. What is more, receiving feedback from peers was found to trigger reflection and awareness.

It is then evident that reflective nature of peer coaching has a potential to foster more critical thinking (Charteris \& Smardon, 2013), make connections between planning, instruction and reflection, and develop a broader perspective for professionalism (Lee \& Choi, 2013). When PSTs are provided with opportunities to reflect more with the use of various tools and activities such as reflective diaries, portfolios, video reflections, and reflective interviews, it is likely for them to develop a more reflective attitude in time which in turn will increase the likelihood of more student involvement and quality of teaching practices (Fatemipour, 2013; Gallego, 2014; Chen et al., 2013; McDonald \& Kahn, 2014)

\subsection{Significance and Aim of the Study}

Most of the studies highlight the need for implementing peer coaching programs in the pre-service contexts since this concept has been underutilized so far. How such programs foster reflectivity is another concern that is pointed out for further investigation. It has been emphasized that engaging PSTs in reflective practice is crucial for their personal and professional development as teachers. However, studies focusing on whether peer coaching embedded in reflectivity and reciprocity would enhance the reflectivity of PSTs are scarce and in the Turkish ELT context, there is no prior study focusing on these aspects during field experience. This study addresses this gap by implementing a RRPC program in a pre-service ELT context (Note 1).

By taking all the positive aspects of RRPC and the essential need for such an implementation identified in the literature 
for the education of PSTs, this study aims at finding out the answers of the following research question:

Is there any change in the reflectivity levels of the PSTs

a. after having training on RRPC?

b. after RRPC practice?

\section{Method}

\subsection{Participants and the Context}

A total of 12 PSTs (nine females, three males) from the ELT department of a Turkish university participated in the study. The participants of the study were selected intentionally based on the ideas of purposeful sampling (Creswell, 2005) to implement RRPC in an ELT education context. All participants were in their final years at the faculty. In the context of the study, the participants took various teaching methodology courses during their four-year training to become English language teachers. Following these courses, they were enrolled in a field experience course to practice teaching based on the theoretical and practical knowledge they gained throughout their education. In this course, the PSTs were assigned to state schools for field experience in pairs or triads and a cooperating teacher in that school guided them. They prepared weekly lesson plans and each of them was responsible for carrying out lessons in the assigned state school based on the prepared plans. RRPC practice was implemented in the field experience course. In order not to put a limit for participants' giving and receiving feedback each other through peer coaching, the supervisor did not give feedback throughout the study. The PSTs received feedback from the supervisor after the completion of the RRPC program based on the video recordings of their teaching performances. The participants volunteered to take part in the study and all of them signed consent forms prior to the study. They were assured about the confidentiality of their participation and collection of data. Since the effectiveness of the study relied heavily on the active and collaborative participation, PSTs in the study were also informed that they could withdraw anytime from the study.

\subsection{Implementation of RRPC Program}

Research has put forward that some conditions are precisely required in order to design and implement a successful peer coaching program in the pre-service context (Hasbrouck \& Christen, 1997; Bowman \& McCormick, 2000; Trautwein \& Ammerman, 2010).

In this study, observation forms and checklists were designed to provide structured observations since this was the first condition necessary for the success of a peer coaching program. That is, participants used these specific tools to make the best of the observations and give feedback based on their actual performances. Moreover, the PSTs received training prior to the actual practice of the peer coaching experience as the second required condition. Most of the studies on peer coaching revealed that a significant amount of time was required teachers to be effective coaches. The participants were also involved in debriefing which constituted the final condition for an effective peer coaching program. Specific attention was given to the design and implementation of the post-conference sessions in which the observed teacher and the coaches discussed the lesson and shared feedback. What is more, clear goal setting, voluntary participation, confidentiality, assessment of the peer coaching process and its impacts, and ongoing institutional support were taken into account throughout the study as these were considered important for the success of a peer coaching program (Huston \& Weaver, 2008). The following steps were followed in the design and implementation of the peer coaching practice:

1. Consent form was designed and all participants signed this form to verify their voluntary participation in the study.

2. Training sessions were implemented before the start of the RRPC. Whole training lasted for twelve weeks. Lesson plans were developed for each week of the training process and the effectiveness of these plans were checked by an expert in the field. In all trainings, various tasks were designed to enhance the implementation of RRPC process. For the purposes of the study, the training included four basic parts: training on reflection and reflective thinking; training on RRPC; training on the use of observation forms; and training on reflective diary keeping.

3. The participants were assigned to peer coaching groups. Each group consisted of three pre-service teachers and a total of four groups were formed.

4. Throughout training sessions, it was observed that the participants could not organize effectively pre and post conferences in order to coach each other. The meetings were rather hasty and careful organization was required for effective implementation of RRPC sessions. Thus, cognitive coaching model (Garmston, Linder \& Whitake, 1993; Costa \& Garmston, 2002) was selected as the framework to be used in this study. The cognitive coaching model was introduced to the participants in an additional training session. This model ensured that peer coaching procedure was implemented in a systematic and structured way. 
5. After the training sessions were completed, RRPC sessions started in the fourth week of the semester and peer coaching groups were assigned to state schools for field experience. The whole process of coaching lasted for eight weeks. Each participant was required to teach one class hour as part of the field experience course; thus, the peer coaching was held once a week for each participant. The participants were involved in RRPC through pre-conference-observation-post-conference cycle.

6. Two intervention sessions were planned to check the effectiveness of the RRPC practice. The videotaped samples of pre-conference-observation-post-conference cycles were used in these sessions along with the checklist designed to guide the participants analyze the sample videos.

\subsection{Data Collection and Instruments}

Data were collected through a mixed method study design. Quantitative data were gathered through The Profile of Reflective Thinking Attributes to detect any change in the reflectivity of the participants. The study proposed a program of RRPC practice to be used in PST education context and the study reported here involved identifying any change PSTs experienced before and after the implementation of such program. Moreover, to support the quantitative findings to reveal any change in the reflectivity levels of the participants, qualitative data were gathered through reflective diaries, video recordings of post-conference sessions and focus-group interviews. Excerpts were taken from qualitative sources to support the findings and to provide more insight into the reflective practices of the PSTs.

\subsubsection{The Profile of Reflective Thinking Attributes}

The aim of this study was to find out whether there was any change in the reflectivity levels of the PSTs (a) after they received training on RRPC and (b) after RRPC practice. In order to answer this question, a quantitative instrument, namely The Profile of Reflective Thinking Attributes developed by Taggart and Wilson (2005) was used.

The instrument was based on different reflectivity levels; namely, technical, contextual and dialectical levels respectively which followed a hierarchical order. It consisted of a total of 30 statements on a four point Likert type scale ranging from "Almost always" to "Seldom". The statements required the participants select the indicator that best reflected agreement about the situations when they faced with problems and when preparing, implementing and assessing a lesson. The Profile of Reflective Thinking Attributes was a self-scoring instrument specifically designed for teachers in pre-service or in-service period and aimed at determining the reflectivity levels of the teachers based on some attributes associated with reflective thinking and practice. It was reported that this instrument could be used with practitioners to create awareness on the current reflective thinking levels as well as to detect increase in the reflectivity of the teachers when used before and after a reflective practice activities and sessions.

Since the original version of the instrument was developed in another cultural context, there was a need to assess the internal reliability to use it in the context of the study. In order to use the instrument for detecting the reflectivity levels of PSTs in the study context, internal consistency of the instrument was calculated. The Profile of Reflective Thinking Attributes was distributed to 135 pre-service teachers. Cronbach Alpha coefficient was calculated and it was found 0.77 . Other than the total internal coefficiency, item coefficiencies were also calculated and as a result of this analysis, no items were excluded from the instrument and it was found reliable.

\subsubsection{Reflective Diaries}

For the purposes of the study, participants wrote reflective diaries upon the RRPC experience to identify any change related to their reflectivity. Reflective diaries are assumed to help PSTs habitually reflect on the teaching experience and engage in reflection as a lifelong experience (Trautwein \& Ammerman, 2010). Thus, reflective diary appeared as an appropriate instrument to be used in this study.

To provide qualitative support for exploring whether there was any change in the reflectivity levels of the PSTs after receiving training on RRPC, participants wrote a single diary upon the completion of the trainings. Furthermore, to support the quantitative findings regarding the change in the level of reflectivity and to explore participants' perceptions about the RRPC procedure, one diary taken from the beginning of the study and one diary taken from the end of the study for each participant on their teaching practices were analyzed for research purposes. The rationale behind taking the initial and final diaries for analyses was to display participants' perceptions at the beginning and at the end of the study. In this way, change in their reflectivity and perceptions became more visible and the effects of the study on the PSTs with respect to their opinions and feelings were revealed.

\subsubsection{Video Recordings}

In order to give a sound answer to the research question (b), video recordings of the post-conference phase of the peer coaching sessions following the actual teaching experience were used along with reflective diaries. Skinner and Welch (1996) highlight the need for recording the peer coaching interactions among the teachers for further analysis. In order 
to highlight the change in reflectivity considering the beginning and end of the study, two of the post-conference sessions for each group were used for analysis. The first recording was from the beginning of the process and the other one was from the end of the RRPC experience. In this way, whether the PSTs were reflective in coaching each other and their progress in reflectivity upon the completion of the study could be seen.

\subsubsection{Focus-group Interviews}

Following the completion of the study, all participants were interviewed through focus-group interviews. Rather than one to one interviews, focus-group interview process was chosen for the study since this process was advantageous when the interaction among respondents provided best information, and when they were similar to and cooperated with each other (Creswell, 2005). General, open-ended questions were asked in the interviews in order to detect any changes in their reflectivity (see Appendix A). Participants were allowed to interact with each other and comment on each other's responses based on their experience throughout peer coaching. Similar to the reflective diaries, the interviews were conducted in participants' native language in order not to create anxiety stemming from language limitations, and to make them feel relaxed and intimate in their responses. All focused group interviews were videotaped and transcribed verbatim.

\subsection{Data Collection Procedures}

Data were collected following a seven-step procedure described below:

1. The Profile of Reflective Thinking Attributes was administered to the participants for the first time prior to the training sessions.

2. Following the completion of the training sessions, The Profile of Reflective Thinking Attributes was administered to the participants for the second time to find out whether training made any difference on the reflectivity levels. Time elapsed between the first and the second application of the instrument was twelve weeks.

3. After the completion of the training sessions, participants were asked to write reflections about whether training made any difference in their reflectivity.

4. Post-conference parts were recorded to provide qualitative support for the quantitative findings regarding whether RRPC made any difference in the reflectivity of the participants. The initial and final recordings of post-conferences sessions were taken for analysis.

5. Participants wrote one reflective diary about the trainings and weekly reflective diaries about their teaching practices. Two of these diaries, the first and the last one, were taken for analysis to provide qualitative support about the change in their reflectivity.

6. Upon the completion of the RRPC sessions, The Profile of Reflective Thinking Attributes was administered to the participants for the third and the last time. The data gathered through this instrument was used to find out whether the practice of RRPC made any changes in the reflectivity levels of the participants.

7. Focus-group interviews were carried out following the completion of the RRPC process. All participants took part in interviews and they were conducted in appropriate hours both for the researcher and the participants.

\subsection{Data Analysis Procedures}

This study was based on a mixed method design; thus, both quantitative and qualitative analyses were carried out. The quantitative instrument, namely The Profile of Reflective Thinking Attributes, categorized the reflectivity of the participants as 'technical', 'contextual', and 'dialectical' based on the scores they gained from the instrument. In the analysis of the instrument, the numbers of the circled indicators were tallied, and then the indicators were multiplied by the tally number to arrive at a sub-total. The four sub-totals were added and the score gained as a result of this calculation was used to categorize the reflectivity levels of the participants. The participants responded to this questionnaire three times: before trainings, after trainings and at the end of the study. Wilcoxon signed-ranks for paired samples test was computed for three times as the data were suitable for non-parametric analysis.

In order to support the quantitative findings regarding the change in reflectivity after the trainings and the RRPC practice, reflective diaries written for these purposes were analyzed. The reflectivity levels in these diaries were analyzed by three separate raters based on the reflective levels identified by Taggart and Wilson (2005). In the initial and final diaries, three raters decided on whether the participants' reflections on their teaching performances were in the 'technical', 'contextual' or 'dialectical' levels of reflectivity. The instances of different levels of reflectivity in the initial diaries were compared with the ones in the final reflective diaries to see the difference in the level of reflectivity. Quotations from the participants' own expressions regarding their reflections on teaching performances were excerpted. Specific attention was paid to select quotations in which the change in a participant's level of reflectivity could be identified. These data were used to support the quantitative findings pointing at the change in the level of reflectivity after the RRPC practice. 


\section{Results}

\subsection{Change in the Reflectivity Levels of the PSTs}

a. after training on RRPC

b. after RRPC experience

One of the aims of this study was to detect any change in the reflectivity of the PSTs after they received training on RRPC program. Table 1 below shows the results of the Wilcoxon Signed-Rank test for the scores gained from Profile of Reflective Thinking Attributes before and after training.

Table 1. The Results of the Wilcoxon Signed-Rank Test for the Profile of Reflective Thinking Attributes Scores Before and After Training

\begin{tabular}{cccccc}
\hline $\begin{array}{l}\text { Pre test-Post test Scores for Before } \\
\text { and After Training }\end{array}$ & $\mathbf{n}$ & Ranking Mean & $\begin{array}{l}\text { Ranking } \\
\text { Total }\end{array}$ & $\mathbf{z}$ & $\mathbf{p}$ \\
\hline $\begin{array}{l}\text { Positive rank } \\
\text { Negative rank }\end{array}$ & 12 & 6,50 & 78,00 & $-3,061$ & .002 \\
$\quad$ Equal & 0 & & & & \\
\hline
\end{tabular}

* Based on negative ranking

As can be seen in Table 1, there is a statistically significant difference between pre test and post test scores of the participants $(\mathrm{z}=-3,061, \mathrm{p}<.02)$. The results of the Wilcoxon Signed-Rank Test for The Profile of Reflective Thinking Attributes scores before and after training indicated that there was an increase in the participants' reflectivity scores. This finding puts forwards that the PSTs' reflectivity advanced as they received training on RRPC.

Other than the change in the level of reflectivity following the trainings, Wilcoxon Signed-Rank test was also utilized to detect any difference in the reflectivity scores of the participants before and after they were engaged in the RRPC practice. Hence, the statistical results related to the signed-rank test displayed the difference in the scores of the participants after they finished receiving trainings and after the implementation of RRPC was completed. Table 2 below demonstrates the results of the Wilcoxon Signed-Rank test computed for the scores of The Profile of Reflective Thinking Attributes before and after the RRPC practice.

Table 2. The Results of the Wilcoxon Signed-Rank Test for the Profile of Reflective Thinking Attributes Scores Before and After RRPC Practice

\begin{tabular}{cccccc}
\hline $\begin{array}{l}\text { Pre test-Post test Scores for Before } \\
\text { and After Practice }\end{array}$ & $\mathbf{n}$ & Ranking Mean & $\begin{array}{l}\text { Ranking } \\
\text { Total }\end{array}$ & $\mathbf{Z}$ & $\mathbf{p}$ \\
\hline Positive rank & 12 & 6,50 & 78,00 & $-3,065$ & .002 \\
Negative rank & 0 & & & & \\
Equal & 0 & & & & \\
\hline
\end{tabular}

* Based on negative ranking

According to the results presented in Table 2, there is a statistically significant difference between the 'before' and 'after' scores the participants got from the instrument $(\mathrm{z}=-3,065, \mathrm{p}<.02)$. That is, the participants' reflectivity increased after they were involved RRPC practice. This result was in parallel to the one related to 'before' and 'after' training scores. The participants' reflectivity advanced after they received training and it continued to change in a positive direction as they got into the actual practice of RRPC. Although the difference between before and after practice mean scores were not as high as the ones between before and after training scores, it was obvious from the statistical analysis that being involved in RRPC practice contributed to changes in the reflectivity on the participants' behalf.

Although positive change in the participants' reflectivity was obvious from two signed-rank tests, a further Wilcoxon Signed-Rank test was computed to detect the difference in the reflectivity before the participants received training and after they completed practice in RRPC. In this way, the overall picture of the change in participants' reflectivity throughout the study was displayed. Table 3 presents the results of the Wilcoxon Signed-Rank test computed for the scores of the participants before they received training and after they finished RRPC practice.

Table 3. The Results of the Wilcoxon Signed-Rank Test for the Profile of Reflective Thinking Attributes Scores before Training and After RRPC Practice

\begin{tabular}{lcclcc}
\hline $\begin{array}{l}\text { Pre test-Post test Scores for Before } \\
\text { Training and After Practice }\end{array}$ & n & Ranking Mean & $\begin{array}{l}\text { Ranking } \\
\text { Total }\end{array}$ & $\mathbf{Z}$ & p \\
\hline Positive rank & 12 & 6,50 & 78,00 & $-3,061$ & .002 \\
Negative rank & 0 & & & & \\
$\quad$ Equal & 0 & & & & \\
\hline
\end{tabular}

* Based on negative ranking 
As it is shown in Table 3, there is a statistically significant difference $(\mathrm{z}=-3,061, \mathrm{p}<.02)$ between the scores of the participants before they started trainings and after they completed RRPC practice. This finding indicated that the participants' reflectivity increased throughout the study. As a result, when the overall scores of the participants they gained from The Profile of Reflective Thinking Attributes at the beginning and at the end of the study were taken into consideration, receiving training and being engaged in RRPC practice helped them to progress in reflectivity.

Apart from the descriptive and statistical analyses based on the overall reflectivity scores of the participants, the reflectivity levels of the participants needed to be identified in order to give a sound answer to the research question (a and b). The reflectivity levels were analyzed as the technical, contextual and dialectical levels. These levels were found following the key for categorization. Due to the categorical distribution of the scores according to the reflectivity levels and the small number of the participants in the study, only the descriptive statistics was computed to show whether there was any change in the reflectivity levels of the participants. Table 4 displays the descriptive results of the distribution of the participants' reflectivity levels.

Table 4. Distribution of the Participants' Levels of Reflectivity before Training, after Training and after Reflective Reciprocal Peer Coaching Practice

\begin{tabular}{cllllll}
\hline Levels of Reflectivity & $\mathbf{N 1} *$ & $\mathbf{\%}$ & $\mathbf{N 2} * *$ & $\mathbf{\%}$ & $\mathbf{N 3} * * *$ & $\mathbf{\%}$ \\
Technical & 6 & 50 & 0 & 0 & 0 & 0 \\
Contextual & 6 & 50 & 11 & 91.7 & 5 & 41.6 \\
Dialectical & 0 & 0 & 1 & 8.3 & 7 & 58.4 \\
TOTAL & $\mathbf{1 2}$ & $\mathbf{1 0 0}$ & $\mathbf{1 2}$ & $\mathbf{1 0 0}$ & $\mathbf{1 2}$ & $\mathbf{1 0 0}$ \\
\hline
\end{tabular}

*Number of participants before training

** Number of participants after training

*** Number of the participants after RRPC practice

As displayed in Table 4, there was a change in the reflectivity levels of the participants before and after training on RRPC. Before trainings began, six of the participants were in the technical level and six of them were in the contextual level. None of the participants had the dialectical level of reflectivity. Six of the participants, who were in the technical level before receiving training, reached the contextual level after the training period. At the end of the trainings, eleven of the participants were in the contextual level of reflectivity. One participant who was in the contextual level before training moved to the dialectical level after receiving training on RRPC. There was no participant who stayed in the technical level of reflectivity at the end of the trainings. A similar result was true for after RRPC practice as there was no participant who had the technical level of reflectivity after being engaged in RRPC practice. After the PSTs were involved in RRPC, six of them who were identified in the contextual level of reflectivity before RRPC practice advanced to the dialectical level of reflectivity. One PST who was in the dialectical level of reflectivity before RRPC practice began stayed in the same level of reflectivity at the end of the practice. As a result, five of the participants were in the contextual level whereas seven of them were in the dialectical level at the end of the study. It was clear from these descriptive results that receiving training and engaging in RRPC practice caused changes in the reflectivity levels of the participants along with an increase in their reflectivity.

Quantitative results related to the change in the reflectivity levels of the participants following the training procedure and the RRPC practice were also supported by qualitative data. As for the trainings, the participants were required to write a reflective diary at the end of the training procedure on whether receiving training caused any change in their reflectivity. All of the participants agreed that being trained on various aspects of RRPC helped them in a positive way. The quotations taken from the diaries served as a qualitative back up of the quantitative findings regarding the change in the level of reflectivity at the end of the trainings. However, rather than giving exact answers to the question asking the change in the level of reflectivity, the participants were mostly concerned about the effects of training. Hence, their reflections regarding the effects of training were beyond the scope of this paper and focus of another study. Although not all the participants directly commented on the change of reflectivity, the following excerpts illustrate how the participants viewed the change in their reflectivity:

(1). "I think there is a definite change in my reflectivity. I started to question many aspects about my own teaching. I can't tell exactly what my actual level of reflectivity is; I think it will become more obvious at the end of the following semester when we will be engaged in peer coaching. But I can say that I'm moving from the technical level to the more advanced levels." (PST4-Reflective diary on training)

(2). "Before the trainings, I think my level of reflectivity was absolutely in the technical level. Preparing the best lesson plan and the materials were all my concern. I never questioned what I did. But now, I begin to see the big picture. I understood the importance of reflective viewpoint. There are more important things such as the students. I can't say my level is in the dialectical level now, but it is advanced to the contextual 


\section{level for sure”. (PST12-Reflective diary on training)}

As it was displayed in the excerpts (1) and (2) above, the PSTs began to realize the importance of reflection and the issues related to it after the training. They felt a change in their reflectivity when they received training on various aspects of RRPC. It was evident from the excerpts above that although the participants were not yet engaged in actual RRPC practices in the training procedure, receiving training caused a positive change in their approach to teaching. The participants reflected similar ideas of change and progress in their reflectivity both in their reflective diaries and post-conference sessions that took place during RRPC practice.

Although no participant resided in the technical level according to the results of quantitative findings at the end of training, when the initial reflective diaries kept during the RRPC practice period were analyzed, many instances of technical level reflections were identified indicating the bottom of Taggart and Wilson's (2005) hierarchical order. The participants in the present study who produced reflections in the technical level were mostly concerned with achieving the planned outcomes, the order of the activities, the materials, following the stages of a lesson, and time management issues. This technical level of reflectivity could be seen in the following excerpt in which the student teacher was reflecting on his listening lesson:

(3). "Today I used a computer for the song. I was worried about time management since handling the technical materials is not always easy for me. But, nothing happened and I was able to follow my plan. I only could not do the last activity since the students hurried for the break time." (PST2-First reflective diary on teaching performance)

The extract above was a typical example of the technical level of reflectivity. The main concern of the PST was mainly following the lesson plan and handling the technical instruments used in the lesson. As the participants progressed in conducting peer coaching cycles and they were involved in RRPC practice, the change in their reflectivity became evident. Throughout their progress, their expressions involved fewer instances of technical level of reflectivity and mostly the contextual level of reflectivity expressions were identified in the final diaries. Such change is displayed in the following excerpt that belongs to the same student teacher's (PST-2) final diary:

(4) "I used real objects today and I couldn't imagine how enjoyable the lesson could be! Doing experimental things in class and having students live some instances of English really works. I theoretically knew that real objects were useful, but preparing them carefully for use in practice and seeing the real effect on the students motivated me to pay more attention to my choices." (PST 2-Last reflective diary on teaching performance)

It was apparent from the excerpt above that the PST produced reflections at the contextual level of reflectivity. That is, she was concerned about her choices, the possible effects of these choices and bridging the gap between theory and practice. This PST was in the technical level of reflectivity prior to the RRPC practice and her reflectivity was centered on the technical aspects of the lesson. The analysis of the final reflective diary of the same PST revealed that her reflections began to include concerns about analyzing the classroom environment, the students, and taking actions with regard to these concerns. Throughout the study, the PST's concern moved from the activities and materials to their effect on the students and their needs.

In addition to the situation above, some PSTs started from the contextual level of reflectivity as revealed from the analyses of the first diaries. That is, there were expressions regarding concerns about student understanding, their needs and the learning environment rather than the technical aspects of teaching. The following excerpt, in which the student teacher is reflecting on her writing lesson, is an example for the contextual level of reflectivity in the initial diaries:

(5). "I taught how to write a fairy tale to the seven grades. My activities did not work as the students were not interested in the topic. I understood that the first rule is to get the attention and find out the interesting topics. My activities were all good but the students needed something else." (PST 10- First reflective diary on teaching performance)

In the excerpt above, the concern for students and their needs could be seen. The progress in the participant's level of reflectivity continued throughout the RRPC practice. After being engaged in RRPC practice, this participant produced reflections in the dialectical level. Such change in this participants' level of reflectivity was visible in the subsequent excerpt:

(6). "For my writing lesson today I thought about teaching how to write a card for mothers' day. Then I thought about the general profile of my students and gave up this idea. Majority of the students are coming from lower socio-economic backgrounds and their parents are divorced. Some of them are away from their mothers. Some students never saw their mother or are left by them. I did not want to upset these students and remind them of bad memories. It wouldn't be ethical." (PST 10- Last reflective diary on teaching 
performance)

As could be noticed in the preceding excerpt, the PST's reflection was in the dialectical level of reflectivity since she took the ethical issues into consideration and made decisions accordingly. The same student did not take the ethical or moral considerations into account in the initial reflections and produced mostly contextual level reflections beforehand. When her last reflective diary was analyzed, it was evident that the participant progressed in her level of reflectivity and she critically reflected on the teaching practices by taking the environment of teaching into account.

In addition to the reflective diaries, post-conference sessions provided qualitative data to support both the quantitative findings and the qualitative findings gathered from the reflective diaries related to the change in the level of reflectivity. The change in the level of reflectivity was visible when the first and the last post-conference sessions were compared. The excerpt below was taken from the first post-conference session conducted on the teaching performance of a PST (PST-9). Another PST (PST-8) was giving feedback:

(7). "The presentation part was good. The pictures you used were colorful and their size was also good. But you forgot to stick some of the pictures on the board. Besides, you did not give time for students to write what was on the board to their notebooks. I think your voice was a little bit lower but the timing of the lesson was good." (PST 8-First post-conference session)

The excerpt above was a sample to technical level of reflectivity. The PST's (PST-8) all interest was bestowed upon evaluating the materials for their size, commenting briefly on time management and voice use. What is more, this participant commented on the technical aspects without reflecting much on feelings and views that drew his commentary. Rather, the reflection was like reading the notes taken during the observation time regardless of analysis of the lesson observed. That is, the learning environment, alternative practices or underlying reasons of classroom practices were not mentioned.

When the final post-conference session of the same PST were analyzed, change in their reflectivity became evident. The following excerpt displayed the change in the reflectivity level of the same participant above (PST-8) in her final post-conference session:

(8). "Your pictures were very nice, they made everything clear for the children...but I can't tell the same thing for your context. It was... how can I say...higher than their language level. You got their attention with the pictures but when you started to create the context... it became boring. Why don't you make simple sentences and choose a very simple context for the fifth graders next time? (turns to other peer) I think this is true for all of us!" (PST 8-Last post-conference session)

The level of reflectivity in this excerpt was identified as the contextual level since the PST commented on the effects of certain practices on students and alternative practices for younger students in lower language levels. In the initial post-conferences, this PST's (PST-8) reflections were generally in the technical level and fewer instances of contextual level of reflectivity were found. However, when the final reflections were taken into account as in the example above, it was evident that her reflections were mostly in the contextual level and this time technical level of reflections were fewer.

Some PSTs' reflections in the first post-conferences involved instances of contextual level of reflectivity as well. The excerpt below in which a PST (PST-6) was providing feedback to another PST (PST-5) is a sample of this:

(9). "If I were you I would have difficulty in handling the discussion part. Everybody was saying something and you handled classroom management very well. These students need to be involved in discussions more often. They did not do these kinds of activities before, that's the main problem. If they are interested in, they talk. Of course, English use is not very well, but that's start I think." (PST6-First post-conference session)

It was clear from the preceding excerpt that the participant's reflection was in the contextual level of reflectivity. He pinpointed the actual problem while holding classroom discussions and highlighted the need for designing similar activities to lead students talk more. The PST displayed commitment to the value that students could learn when their attention was drawn. Although technical and contextual levels of reflectivity were highly dominant in the initial post-conference sessions, the instances of contextual and dialectical level of reflectivity expanded when the final post-conference sessions were taken into account. In these sessions, the participants discussed the rationale of classroom practices more often, focused on student learning and they were also concerned with some ethical problems evident in the school environment. The following excerpt illustrates how the PST (PST-6) who had reflections on the contextual level previously displayed dialectical level of reflectivity in the final post-conference:

(10). "Some students are rather isolated from the class. Don't you think so?... They are always on their own, at the back rows...The teachers seem to ignore these students and they get lost...It's not fair. Well, I try to involve them as much as possible and pay attention not to humiliate them in front of their friends. I think we 
should do something for these students. When I become a teacher I will not let these students got lost in the system" (PST 6- Last post-conference session)

The sample excerpt above illustrated that the PST was concerned about ethical issues in the classroom and discussed this aspect with the peers. What is more, the PST displayed self-understanding as a teacher for the ignored students and decided to take action for them in the future. Rather than complaining about low participation of some students, the student teacher viewed the problem situation in an ethical context.

As a result, in the final post-conferences the participants reflected more on the teaching performances in dialectical levels. It was clear that the PSTs started to discuss on ethical and moral issues related to teaching and they displayed self-understanding as teachers.

To support the quantitative findings regarding the change in reflectivity with more qualitative data, the participants were asked to compare their reflectivity before and after the RRPC practice and identify their current levels of reflectivity in the focus-group interviews. All of the participants claimed that there was an obvious positive change in their reflectivity. Before they started reflective reciprocal peer coaching practice, they thought their level of reflectivity was mostly dominated by the technical level but instances of contextual level of reflectivity were evident; however, throughout the practice it advanced more to the contextual and dialectical levels. However, most of them thought their current level of reflectivity was between the contextual and dialectical levels and they needed more opportunities to advance their level to the dialectical level of reflectivity. The following PST excerpt taken from the focus-group interviews exemplified what the participant thought about the change in their reflectivity.

(11). "There is a definite change in my reflectivity. Before this study, I think it was generally the technical level. I was too concerned about the outcomes, materials, the lesson format, but when I think about now...I can't say it is in the dialectical level, I have more to go for this...but I can say it is between the contextual and dialectical levels. I am more concerned about my students, their needs, interests. I do not just prepare a lesson plan just as to prepare one but I think about many factors and make my decisions accordingly. Me and my friends think about 'whys' and 'hows'more often." (PST 3-Focus-group interview)

There were also participants who thought their level of reflectivity mostly advanced to the dialectical level. One of the student teachers expressed this as:

(12). "I believe I am mostly in the dialectical level in my reflections. We even think about the ethical issues in our classrooms and the sociological effects of what we do on the students. I never thought about these beforehand." (PST 7-Focus-group interview)

All in all, the quantitative and qualitative findings regarding the change in the participants' level of reflectivity after the trainings and after the actual RRPC practice indicated that there was a change in the reflectivity levels of the participants. In general, the level of reflectivity advanced from technical to contextual and dialectical levels.

\section{Discussion}

Purpose of the study was to find out whether RRPC practice had any impacts on the reflectivity of the PSTs. The results suggested a change in the reflectivity levels of the participants throughout the study. That is, the PSTs in the study were able to move forward in the reflectivity hierarchy and their levels advanced to contextual and dialectical levels of reflectivity at the end of the study. As the qualitative findings regarding the change in reflectivity unveiled, the PSTs focused on the underlying meaning behind their actions, began to create alternative ways in problematic situations and challenged existing ideas with the help of reflective practices throughout peer coaching experience. This finding manifests the importance of reflection and reflective practices suggested by Taylor (1993), Schön (1987), Smith (1999) and Stein (2000). As highlighted by these researchers, reflective practice helped the participants of the study take a big step for professional development, search for learning opportunities from different sources such as their peers and created changes to form a professional perspective.

With the help of the current practice, the PSTs had a chance to question their actions and gain awareness through reflection. Gün (2011) asserts that all teachers engage in some kind of reflection in every instance they look back at their practices; however, the effectiveness of those reflections is what matters. In this sense, RRPC practice increased the effectiveness of reflections. Such effectiveness might be attributed providing sufficient opportunities for PSTs such as designing specific tools for observation, organizing pre and conference sessions, and offering guidance for reflective practices. These might help them critically reflect on their practices rather than simply thinking about what they do. Merc (2010) also suggests fostering more critical reflection in PST education. Since the reflectivity levels of the participants evolved from technical to higher levels of reflectivity throughout the study, long-term RRPC practice appears as a favorable candidate to foster critical reflection in the PST context.

Throughout the RRPC practice, the participants based their reflections on actual observation of teaching practices, 
analyzed their experiences and formed ideas to take action for new practices. The PSTs built a habitual reflective thinking practice, which in return opened way to reflect on teaching practices in more contextual and dialectical levels. That is, throughout the RRPC practice the participants began to focus more on the students, their needs and alternative practice rather than the mere technical aspects of teaching. Furthermore, some of the participants were even able to reflect on the sociological and ethical aspects of teaching and displayed autonomy as a teacher. In the interviews, they attributed these advances to the crucial role of reflective practice which enlightened the way for professional practice.

Cook et al. (2001) pinpoint that the practitioners need time and opportunities for reflective practice to move upwards in the reflectivity hierarchy. The PSTs in Cook et al.'s (2001) and Griffin's (2003) studies were not able to move to desired levels of dialectical or moral reflectivity since they were deprived of sufficient opportunities and optimum time required for reflective practices. On the contrary, the PSTs in the current study progressed in their level of reflectivity. One reason of this finding might arise from the sufficient amount of time reserved for all process of reflective reciprocal peer coaching starting from the trainings. Reflective thinking does not generate the desired outcomes in a limited time and the impacts cannot be easily seen in classroom practices immediately. Since the whole process of RRPC implemented here lasted for a whole academic year, the participants might be able to see reflective practice as part of the academic success. What is more, the tools such as reflective diaries, observation forms and pre-conference-observation-post conference checklists developed to foster reflectivity along with the coaching model used in this study would also have effects on making reflective practice a systematic way of thinking for the participants. With the help of this model, the PSTs might become aware of what lies behind their practices as suggested by Ellison \& Hayes (2003). What is more, careful organization and systematic fashion of reflectivity as described here might serve as a way to foster guided observation (Anderson et al., 2005) to maximize the necessary opportunities required for reflection.

Since there was a positive change in the reflectivity levels of the participants and no negative view was detected in the qualitative data about the RRPC practice, the current study can be considered as a success on the behalf of the participant PSTs. This success might be attributed to the commitment for implementing the essential characteristics of peer coaching (Valencia \& Killan, 1998; Becker, 2000; Bell \& Mladenovic, 2008; Briton \& Anderson, 2010) throughout the study. Accordingly, as highlighted by the participants in the qualitative findings, specific attention was paid to sustain a friendly and non-judgmental setting. The PSTs did not evaluate each other; rather they paid attention to learn from experience based on actual classroom observation.

All in all, the findings of this study yield that peer coaching can offer opportunities for PSTs to gain awareness about their own teaching, and thus; improve reflectivity. The results of this study mirror the findings of literature on peer coaching as a beneficial and profitable application for advancement in reflectivity in PST education. Furthermore, the findings of the current practice adds much to the current literature on peer coaching with its emphasis on designing a rather longitudinal and systematic implementation of a peer coaching program based on reflectivity and reciprocity.

\section{Conclusion}

Teachers' continual professional development is crucial to meet the ever-changing needs of the students (Swafford, 1998). For this end, teacher education programs need to prepare future teachers for professional life in an effective way. However, providing professional opportunities for PSTs especially during field experience is a growing challenge for faculties (Huston \& Weaver, 2008). RRPC experience as designed and practiced in this study appears as a suggestion for maximizing the potential of field experience in PST education. It is implied that peer coaching experience based on reflection and reciprocity is more likely to provide an appropriate platform for integrating theory into practice during field experiences of the PSTs. It suggests an alternative way to enhance current teacher education programs with respect to its positive effects regarding the advancement in reflectivity.

Unrecognized value of peer coaching as a collegial process of professional development is highlighted by many researchers (Huston \& Weaver, 2008; Britton \& Anderson, 2010; Lu, 2010; Prince et al., 2010). What is more, it is assumed that peer coaching experience has a potential to boost reflective practices and collaboration when sufficient effort is given to enhance reflective practices (Kurtts \& Levin, 2000; Anderson et al., 2005; Huston \& Weaver, 2005). In parallel with this assumption, the results of the present study have put forward that long-term RRPC experience increased the level of reflectivity and the PSTs benefited much from the current application. RRPC appears as an advantageous practice in PST education since the ultimate aim of teacher education programs is to bring up teachers who are reflective, active and cooperative. What is more, there is a consensus in teacher education that teacher development models should enhance reflective practice (Wallace, 1991; Richards \& Lockhart, 1994; Gun, 2011; Chen et al., 2013). Thus, it can be suggested that the findings of this study would enlighten the way for teacher educators to prepare the necessary materials, activities, tools and training to promote more reflection through a peer coaching program. It is obvious that RRPC practice has positive impacts in evolving PSTs with idle existence in the back rows into active and productive participants. 
As a consequence, it is suggested for teacher educators to encourage PSTs engage in reflective practice throughout peer coaching. One feels more secure and less anxious when $\mathrm{s} /$ he is discussing issues about his/her own teaching. If peer coaching is seen as a part of reflective practice, it will foster cooperation among peers and serve as an effective tool to improve teaching skills. Replication of this study on RRPC in different teacher education contexts and programs may help to compare the effects of RRPC on reflectivity or other aspects. A further study can also be designed in which PSTs come together and discuss the effects and outcomes of a similar practice. In this way, the results of the present study can be expanded to various teacher education contexts.

\section{Acknowledgements}

I would like to thank Prof. Dr. Ilknur Kecik for her invaluable feedback and support throughout this study.

\section{References}

Anderson, N. A., Barksdale, M. A., \& Hite, C. E. (2005). Preservice teachers' observations of cooperating teachers and peers while participating in an early field experience. Teacher Education Quarterly, 32(4), 97-117.

Beavers, D. (2001). Outside the Workshop box. Principle Leadership, May/June, 43-46.

Becker, J. M. (2000). TNLI: Action research: Professional development: Peer coaching for improvement of teaching and learning. Retrieved on December 2011 from http://teachersnetwork.org/tnli/research/growth/becker.htm.

Bell, A., \& Mladenovic, R. (2008). The benefits of peer observation of teaching for tutor development. Higher Education, 55(6), 735-752. http://dx.doi.org/10.1007/s10734-007-9093-1.

Bowman, C. L., \& McCormick, S. (2000). Comparison of peer coaching versus traditional supervision effects. Journal of Educational Research, 93(4), 256-262. http://dx.doi.org/10.1080/00220670009598714

Britton, L. R., \& Anderson, K. A. (2010). Peer coaching and pre-service teachers: Examining an underutilized concept. Teaching and Teacher Education, 26(2), 306-314. http://dx.doi.org/10.1016/j.tate.2009.03.008

Charteris, J., \& Smardon, D. (2013). Second look-second think: A fresh look at video support dialogic feedback in peer coaching. Professional Development in Education, http://dx.doi.org/10.1080/19415257.2012.753931.

Chen, D., Lumpe, A., \& Bishop, D. (2013). Assessment of teacher candidate reflection in e-portfolios. In J. Herrington, A. Couros \& V. Irvine (Eds.), Proceedings of EdMedia: World Conference on Educational Media and Technology 2013 (pp. 1872-1881). Association for the Advancement of Computing in Education (AACE). Retrieved March 10, 2016 from https://www.learntechlib.org/p/112224.

Cook, P. F., Young, J. R., \& Evensen, N. (2001). Using Mediated Learning to Improve the Level of Reflection of Pre-service Teachers. Paper presented to International Conference on Learning Potential: Unlocking Human Potential to Learn, August 19-25, 2001 in Winnipeg, Manitoba, Canada.

Costa, A. L., \& Garmston, R. J. (2002). Cognitive coaching: A foundation for Renaissance Schools. Norwood, MA: Christopher-Gordon Publishers, Inc.

Creswell, J. W. (2005). Educational Research: Planning, Conducting, and Evaluating Quantitative and Qualitative Research. New Jersey: Prentice Hall Publishing.

Dewey, J. (1933). How we think: A restatement of the relation of reflective thinking to the educational process. Lexington, MA: Heath.

Donnelly, R. (2007). Perceived impact of peer observation of teaching higher education. International Journal of Teaching and Learning in Higher Education, 19(2), 117-129.

Ellison, J., \& Hayes, C. (2003). Cognitive coaching: Weaving threads of learning and change into the culture of an organization. Massachusetts: Christopher-Gordon Publishers, Inc.

Farrell, T. (2008). Critical incidents in ELT initial teacher training. ELT Journal, 62(1), 3-10. http://dx.doi.org/10.1093/elt/ccm072.

Fatemipour, H. (2013). The efficiency of the tools used for reflective teaching in ESL contexts. Procedia-Social and Behavioral Sciences, 93, 1398-1403. http://dx.doi.org/10.1016/j.sbspro.2013.10.051.

Gale, T., \& Jackson, C. (1997). Preparing professionals: student teachers and their supervisors at work. Asia-Pacific Journal of Teacher Education, 25(2), 177-191. http://dx.doi.org/10.1080/1359866970250207

Gallego, M. (2014). Professional development of graduate teaching assistants in faculty-like positions: Fostering reflective practices through reflective teaching journals. Journal of the Scholarship of Teaching and Learning, 
14(2), 96-110. http://dx.doi.org/10.14434/josotl.v14i2.4218.

Garmston, R., Linder, C., \& Whitake, J. (1993). Reflections on cognitive coaching. Educational Leadership, 51(2), 57-60.

Griffin, M. L. (2003). Using Critical Incidents to Promote and Assess Reflective Thinking in Pre-service Teachers. Reflective Practice, 4(2), 207-220. http://dx.doi.org/10.1080/14623940308274

Gun, B. (2011). Quality self-reflection through reflection training. ELT Journal, 65(2), 126-135. http://dx.doi.org/10.1093/elt/ccq040

Hasbrouck, J. E., \& Christen, M. H. (1997). Providing Peer Coaching in Inclusive Classrooms: A Tool for Consulting Teachers. Intervention in School and Clinic, 32(3), 172-177. http://dx.doi.org/10.1177/105345129703200308

He, W., Means, T., \& Lin, G. Y. (2006). Field experience tracking and management in teacher development programs. International Journal of Technology in Teaching and Learning, 2(2), 134-147.

Huston, T., \& Weaver, C. L. (2008). Peer coaching: Professional development for experienced faculty. Innovations in Higher Education, 33, 5-20. http://dx.doi.org/10.1007/s10755-007-9061-9.

Joyce, B., \& Showers, B. (2002). Student achievement through staff development. Alexandria, VA: Association for Supervision and Curriculum Development.

Kauffman, D. (1992). Supervision of preservice teachers. Retrieved on October, 2011 from http://www.ericfacility.net/databases/ERIC_Digests/ed344873.html.

Kurtts, S. A., \& Levin, B. B. (2000). Using Peer Coaching with Pre-service Teachers to Develop Reflective Practice and Collegial Support. Teaching Education, 11(3), 297-310. http://dx.doi.org/10.1080/713698980

Ladyshewsky, R. K., \& Ryan, J. (2002). Reciprocal peer coaching as a strategy for the development of leadership and management competency. Focusing on the Student Proceedings of the 11 th Annual Teaching Learning Forum.

Lamaster, K. J. (2001). Enhancing preservice teachers field experiences through the addition of a service-learning component. The Journal of Experiential Education, 24(1), 27-33. http://dx.doi.org/10.1177/105382590102400107

Lee, O., \& Choi, E. (2013). Utilizing Peer Coaching to Facilitate Pre-service Physical Education Teachers' Reflection. The Asia-Pacific Education Researcher, 22(2), 147-154. http://dx.doi.org/10.1007/s40299-012-0007-3

Little, P. F. B. (2005). Peer Coaching as a Support to Collaborative Teaching. Mentoring and Tutoring, 13(1), 83-94. http://dx.doi.org/10.1080/13611260500040351

Lu, H. L. (2010). Research on peer coaching in preservice teacher education-A review of literature. Teaching and Teacher Education, 26(4), 748-753. http://dx.doi.org/10.1016/j.tate.2009.10.015

McDonald, D., \& Kahn, M. (2014). So you think you can teach?- Reflection processes that support pre-service teachers' readiness for field experience. International Journal for the Scholarship of Teaching and Learning, 8(2), 1-34. http://dx.doi.org/10.20429/ijsotl.2014.080218

Merc, A. (2010). Foreign language student teacher anxiety. Unpublished PhD Thesis. Eskisehir: Anadolu University.

Moore, R. (2003). Reexamining the Field Experiences of Pre-service Teachers. Journal of Teacher Education, 54(1), 31-42. http://dx.doi.org/10.1177/0022487102238656

Murray, M., \& Kujundzic, N. (2005). Critical Reflection: A Textbook For Critical Thinking. Québec, Canada: McGill-Queen's University Press.

Pollard, A., \& Tann, S. (1994). Reflective teaching in the primary school: a handbook for the classroom. London: Cassell.

Prince, T., Snowden, E., \& Matthews, B. (2010). Utilising peer coaching as a tool to improve student-teacher confidence and support the development of classroom practice. Literacy Information and Computer Education Journal, 1(1), 49-51.

Puckett, J. B., \& Anderson, R. S. (2002). Assessing field experience. New Directions for Teaching and Learning, 91, 53-60. http://dx.doi.org/10.1002/tl.66.

Richards, J. C., \& Lockhart, C. (1994). Reflective teaching in second language classrooms. Cambridge: Cambridge University Press. http://dx.doi.org/10.1017/CBO9780511667169

Robbins, P. (1991). How to plan and implement a peer coaching program. Alexandria, VA: ASCD.

Rowland, G., Lockyer, L., Carter, L., Patterson, J., \& Hearne, D. (2000). The practicum-A starting point for the development of an on-line learning community of physical and health education professionals. Australian 
Association for Research in Education Conference. AARE Sydney, 4 - 7 December. Retrieved on October 2011 from http://www.aare.edu.au/00pap/row00481.htm.

Schon, D. (1987). Educating the reflective practitioner. San Francisco: Jossey-Bass.

Shantz, D., \& Ward, T. (2000). Feedback, conversation and power in the field experience of preservice teachers. Journal of Instructional Psychology, 27(4), 288-294.

Skinner, M. E., \& Welch, F. C. (1996). Peer coaching for better teaching. College Teaching, 44(4), 153-156. http://dx.doi.org/10.1080/87567555.1996.9932346

Smith, K., \& Lev-Ari, L. (2005). The place of the practicum in pre-service teacher education: The voice of the students. Asia-Pacific Journal of Teacher Education, 33(3). 289-302. http://dx.doi.org/10.1080/13598660500286333

Smith, M. K. (1999). Reflection. Retrieved on May 2007 from http://www.infed.org/biblio/b-reflect.htm.

Stein, D. (2000). Teaching critical reflection: Myths and realities. ERIC Clearinghouse on Adult, Career and Vocational Education.

Swafford, J. (1998). Teachers supporting teachers through peer coaching. Support for Learning,13(2), 54-58. http://dx.doi.org/10.1111/1467-9604.00058

Taggart, G. L., \& Wilson, A. P. (1998). Promoting Reflective Thinking in Teachers. London: SAGE Publications Inc.

Taylor, P. S. (1993). Collaborating to reconstruct teaching: The influence of researcher beliefs. In K. Tobin (Ed.), The Practice of Constructivism in Science Education (pp. 267-297). Washington, DC. AAAS Press.

Topping, K. J. (2005). Trends in peer learning. Educational psychology, 25(6), 631-645. http://dx.doi.org/10.1080/01443410500345172

Trautwein, B., \& Ammerman, S. (2010). From pedagogy to practice: Mentoring and reciprocal peer coaching for pre-service teachers. Volta Review. Retrieved on December 2010 from http://findarticles.com/p/articles/mi_7766/is_201007/ai_n54715790/.

Vacilotto, S., \& Cummings, R. (2007). Peer coaching in TEFL/TESL programmes. ELT Journal, 61(2), 153-160. http://dx.doi.org/10.1093/elt/ccm008

Valencia, S. W., \& Killian, J. P. (1988). Overcoming obstacles to teacher change: Direction from school-based efforts. Journal of Staff Development, 9(2), 2-8.

Wallace, M. J. (1991). Training foreign language teachers. Cambridge: Cambridge University Press.

Weshah, H. A. (2007). Training pre-service teacher education on reflective practice in Jordanian universities. European Journal of Scientific Research, 18(2), 306-331.

Zwart, R. C., Wubbels, T., Bergen, T. C. M., \& Bolhuis, S. (2007). Experienced teacher learning within the context of reciprocal peer coaching. Teachers and Teaching: Theory and Practice, 13(2), 165-187. http://dx.doi.org/10.1080/13540600601152520

Note 1. This paper is derived from an unpublished doctoral thesis dissertation named: A study on reflective reciprocal peer coaching: An application in pre-service English Language Teaching context. It is written by the author S. Ipek Kuru Gonen and is accepted by Anadolu University Graduate School of Educational Sciences, January 2012.

\section{Appendix A-Focus-group interview questions}

1. What do you think about the role of reflective reciprocal peer coaching experience in general?

2. Do you think this experience has any effect on your attitude towards reflectivity? If yes, please explain.

3. Is there any change in your reflectivity before and after reflective reciprocal peer coaching experience? If yes, how?

4. What do you think about your current level of reflectivity?

\section{(cc) BY}

This work is licensed under a Creative Commons Attribution 3.0 License. 